\title{
Where to Give Birth
}

\author{
Wendy C. Budin, PhD, RN-BC, LCCE, FACCE, FAAN
}

\begin{abstract}
In this column, the editor of The Journal of Perinatal Education discusses choices mothers make when deciding on where to give birth. The editor also describes the contents of this issue, which offer a broad range of resources, research, and inspiration for childbirth educators in their efforts to promote, support, and protect natural, safe, and healthy birth.
\end{abstract}

The Journal of Perinatal Education, 22(3), 127-129, http://dx.doi.org/10.1891/1058-1243.22.3.127

Keywords: normal birth, natural birth, safe birth, healthy birth, physiological childbirth education, perinatal education, elective induction

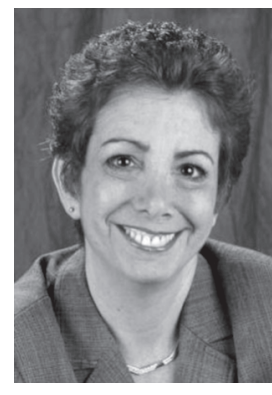

Wendy C. Budin Editor
I was recently asked to speak to a nursing class on Global Perspectives of Maternal Child Health. During the class, a nursing student from Africa whose mother gave birth to her first child in her village with little or no medical interventions and gave birth to her second child (the student) in a hospital in the United States remarked that although both births were physiologically normal, the birth setting and practices affected her mother's lasting impression of the experience. In Africa, her mother was attended by a midwife, and other women in the community provided support throughout her labor and birth. Mother and baby remained together and breastfeeding began immediately. After the U.S. hospital birth, her mother and baby were initially separated. The baby went to a sterile seeming nursery and her mother recalled that she was only able to feed her baby on a 4-hr schedule. At the time her mother believed that in a U.S. hospital was the modern and safest way to give birth; yet, although she didn't question anything at the time, she always felt something was missing from her second birth experience.
The student reflected that it was only after conversations with her mother that both she and her mother began to evaluate how birth setting and the care provided influences the lasting impression of experience.

Fast-forward several decades from when this student's mother gave birth. Here in the United States we are still debating where women should give birth. Pregnant women and their families have a decision to make when it comes to where to give birth. Many still believe the hospital is the safest place for even normal healthy women despite mounting evidence to the contrary. Although hospitals are the most common choice, many women choose to have their babies outside of traditional hospital settings. Some say they are reluctant to give birth in a hospital because of the routine interventions that have become standard practices in our hospitals. It is important for all pregnant women to know their options and the best evidence to support an informed decision when choosing a birth setting.

Recently, the Institute of Medicine (IOM) conducted a two-day public workshop on "Research

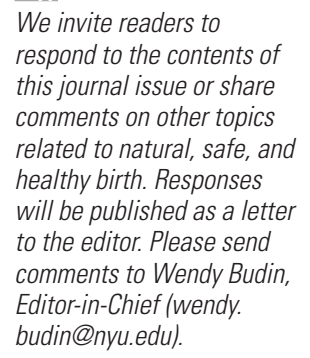
respond to the contents of this journal issue or share comments on other topics related to natural, safe, and healthy birth. Responses will be published as a letter to the editor. Please send comments to Wendy Budin, Editor-in-Chief (wendy. budin@nyu.edu). 
It is important for all pregnant women to know their options and the best evidence to support an informed decision when choosing a

birth setting.

The content of all JPE issues published since October 1998 is available on the journal's website (www.ingenta connect.com/content/springe (jpe). Lamaze International members can access the site and download free copies of JPE articles by logging on at the "Members Only" link on the Lamaze website (www .lamaze.org). workshop featured presentations from invited speakers and discussions that highlighted research findings that advance our understanding of the efinstitutional settings on maternal labor, clinical and other birth procedures, and birth outcomes. These settings include conventional hospital labor and delivery wards, alternative birth settings that may be hospital affiliated or freestanding, and home births. In this issue of The Journal of Perinatal Education, our invited guest author Wendy Gordon describes some of the discussion during the workshop and outcomes and recommendations that may inform a future consensus study to address these concerns.

\section{IN THIS ISSUE}

Continuing the practice of advancing the Lamaze birth by sharing birth stories, this issue's "Celebrate Birth!" column features a family-centered cesarean her twin grandchildren. Because of good prenatal education, a well-chosen, dedicated care provider, and parents with focus, a beautiful outcome was achieved. Tumblin shares this special birth story in
Issues in the Assessment of Birth Settings." The fects of maternal care services in different types of International mission to promote normal healthy birth story by Ann Tumblin describing the birth of the hopes that it will encourage other childbirth educators to present various options for cesarean in their classes if a cesarean birth is necessary.

In this issue's featured article, Wendy Gordon, CPM, LM, MPH, Assistant Professor, Bastyr University Department of Midwifery, Division of Research, Midwives Alliance of North America, and Board Member, Association of Midwifery Educators, discusses outcomes from a two-day workshop held on March 6-7, 2003 on "Research Issues in the Assessment of Birth Settings," hosted by the prestigious Institute of Medicine (IOM) and sponsored by the W.K. Kellogg Foundation. Participants included some of the greatest minds in research and the provision of maternity care including epidemiologists, public health professionals, midwives, nurses, pediatricians, and obstetricians. The discussions were supported by 30 years of research. The takeaway message reflecting agreement by most presenters was that normal physiologic birth is best for mother and baby and should be the goal of all settings and practitioners.

Also in this issue, authors Risisky, Asghar, Chaffee, and DeGennaro present finding from their qualitative nonexperimental thematic analysis conducted at a hospital-based midwifery practice to explore women's perceptions using the CenteringPregnancy model of group prenatal care and its impact on pregnancy, delivery, and postnatal care. The findings conveyed three broad themes: program experience, midwife relationship, and support. These findings showed the enhanced opportunity for education, learning, and interpersonal support provided by CenteringPregnancy to expectant mothers had a positive impact on their pregnancy experiences.

Rowe, Barnes, and Sutherns discuss how the transition from maternity services to community child health services on discharge from hospital occurs at a potentially vulnerable time for women in their transition through the childbearing/early parenting continuum. They suggest that the ideal attributes of services that support women and their families during this time include continuity of care, service integration, and delivery in accessible, communitybased contexts. The purpose of their study was to investigate aspects of maternal experience of mothers attending with their infants a publicly funded drop-in postnatal health-care service, as well as their reasons for attending and their perceptions of its usefulness to them as a mechanism of continuity and a source of support.

In this issue's continuing education module "Fetal Monitoring: Creating a Culture of Safety With Informed Choice," Lisa Heelan shares evidencebased recommendations formed by consensus among professional and governmental groups that intermittent auscultation is safer to use in healthy women with uncomplicated pregnancies than electronic fetal monitoring (EFM). In this informative article, the author describes the history and current use of EFM, benefits, risks, and barriers that impact the laboring woman's ability to give informed choice regarding fetal monitoring. Lack of informed choice denies a woman her right to be in control of her birth experience, and is in opposition to a woman's right to autonomy and self-determination.

Authors Logsdon, Eckert, Tomasulo, and Myers present findings from their replication study on "SelfEfficacy and Teaching About Postpartum Depression (PPD)" that suggest teaching new mothers about PPD is predicted by a nurse's self-efficacy related 
to PPD teaching, expectations for teaching from nursing leaders, PPD continuing education, teaching experience on other topics, and experience with observing other nurses teaching patients about PPD. The results of the study demonstrate the importance of the climate created by the nursing leaders in which teaching about PPD is expected.

Regan, McElroy, and Moore report the findings from their mixed-methods study on factors that influence women's decisions about birth, with the view that women's decision making about birth can affect the use of cesarean surgery. Data were collected from focus groups and structured postpartum interviews and was analyzed using the Consensual Qualitative Research method. Authors reported on various factors that were influential in making decisions about birth and found that hearing stories about birth and/or attending a birth appeared to have the most lasting effect on birth choices.

WENDY C. BUDIN is the editor-in-chief of The Journal of Perinatal Education. She is also the director of nursing research at NYU Langone Medical Center and adjunct professor at New York University, College of Nursing. She is a fellow in the American College of Childbirth Educators and is a member of the Lamaze International Certification Council. 